\title{
BMJ Open Examination of psychosocial predictors of Chinese hospital pharmacists' intention to provide clinical pharmacy services using the theory of planned behaviour: a cross-sectional questionnaire study
}

\author{
Yuan He, ${ }^{1}$ Fan Yang, ${ }^{2}$ Dongqin $\mathrm{Mu},{ }^{3}$ Yuan Xing, ${ }^{4}$ Xin $\mathrm{Li}^{4,5}$
}

To cite: He Y, Yang F, Mu D, et al. Examination of psychosocial predictors of Chinese hospital pharmacists' intention to provide clinical pharmacy services using the theory of planned behaviour: a cross-sectional questionnaire study. BMJ Open 2016;6:e012775. doi:10.1136/bmjopen-2016012775

- Prepublication history for this paper is available online. To view these files please visit the journal online (http://dx.doi.org/10.1136/ bmjopen-2016-012775).

Received 25 May 2016 Revised 3 September 2016 Accepted 8 September 2016

CrossMark

For numbered affiliations see end of article.

Correspondence to

Dr Xin Li;

xinli@njmu.edu.cn

\section{ABSTRACT}

Objectives: Main study aim was as follows: (1) to explore the usefulness of the theory of planned behaviour (TPB) model in predicting Chinese hospital pharmacists' intention to provide clinical pharmacy services (CPSs), including auxiliary CPSs and core CPSs; (2) to identify the main factors affecting the Chinese hospital pharmacists' intention to provide core CPSs based on TPB quantitatively.

Design: Cross-sectional questionnaire study. Setting: The study was conducted in 22 general hospitals in seven cities located in the eastern and western part of China.

Participants: 416 hospital pharmacists (292 (70.2\%) female) entered and completed the study.

Primary and secondary outcome measures:

Quantitative responses with hospital pharmacists' intention, attitude, subjective norms (SNs) and perceived behavioural control (PBC) over provision of CPSs and their past behaviour (PB)-related CPSs.

Results: The structural equation model analysis found that attitude $(p=0.0079, \beta=0.12)$, SN ( $p=0.038$, $\beta=0.10$ ) and the pharmacists' intention to provide auxiliary CPSs ( $p=0.0001, \beta=0.63$ ) significantly predicted of their intention to provide core CPSs, accounting for $54.0 \%$ of its variance. Attitude $(p=0.0001, \beta=0.35)$, PBC ( $p=0.0182, \beta=0.12)$ and $P B$ $(p=0.0009, \beta=0.15)$ are significant predictors of pharmacists' intention, accounting for $21 \%$ of the variance in pharmacists' intention to provide auxiliary CPSs.

Conclusions: The TPB with the addition of PB is a useful framework for predicting pharmacists' intention to provide CPSs in Chinese hospital care context. Strategies to improve hospital pharmacists' intention to provide CPSs should focus on helping the individuals related medical care see the value of CPSs, altering their perception of social pressure towards core CPSs and the removal of obstacles that impede the translation of intentions into behaviour.
Strengths and limitations of this study

This is the first kind of study that was conducted in China to examine hospital pharmacists' intention to provide clinical pharmacy services (CPSs) within the theoretical framework of the theory of planned behaviour (TPB) in China. Our findings provide a better understanding of the hospital pharmacists' willingness to provide different types of CPSs in China.

- It is also the first time for the Chinese researchers to identify the main factors affecting the pharmacists' intention to provide core CPSs based on TPB quantitatively, which will provide evidence for improving management strategy.

- Our sample came from urban general hospitals, limiting generalisability to the entire healthcare systems. Owing to memory biases, consistency or social desirability, self-reported measures of behavioural intention and past behaviours (PBs) can possibly overestimate the association between PB and behavioural intention.

- This cross-sectional study is unable to make causal inferences between TPB factors and actual behaviour because it did not control for all possible confounding variables.

\section{INTRODUCTION}

The traditional tasks of a hospital pharmacist predominantly involved the compounding and dispensing of medications. With the development of the concept and practice of patient-oriented hospital pharmacy in western developed countries, the profession has since evolved to become recognised as an essential part of cognitive clinical services. It is named as clinical pharmacy by American College of Clinical Pharmacy (ACCP) and the definition is as follows: a 
health science discipline in which pharmacists provide patient care that optimises medication therapy and promotes health, wellness and disease prevention. ${ }^{1}$ Therefore, Clinical Pharmacy Services (CPSs), which are applications of clinical pharmacy, focus on patientcentred care and medication-related outcomes optimisation for patients throughout the medicationmanagement process. ${ }^{2}$ CPSs are firmly established in many developed countries, which have been demonstrated to promote appropriate prescribing, reduce adverse drug events, prevent medication errors, decrease patients' length of stay, lower mortality rates and reduce medical expenses. ${ }^{3-6}$ Hospital pharmacist, the provider of CPSs, now routinely participates in multidisciplinary and specialty ward rounds, with the explicit aim of reviewing and optimising the appropriateness of medications prescribed and providing patient education.

However, for this change to take place, hospital pharmacists need to overcome psychosocial barriers to providing patient-centred services. For instance, they usually feel constrained by new job roles, feel uncomfortable with new workplaces and anticipate resistance from physicians and patients. As a result, they are often reluctant to provide non-compounding and non-dispensing services. $^{7-10}$ As healthcare systems grant pharmacists broader roles, it is necessary for health authority to better understand how to circumvent these fears and encourage pharmacists to expand their scopes of practice.

Unlike many Western countries, CPSs have not been incorporated into routine inpatient care in most Chinese hospitals. In China, the pharmacists are quite detached from the healthcare team in hospital setting. To meet the rapid development of the hospital pharmacy and improve the rational clinical use of drugs in China, the National Health and Family Planning Commission (NHFPC) of China has been issuing a series of regulations to establish the institution of CPSs in Chinese hospitals since 2005. Despite this NHFPC initiative, full-time CPSs have made limited progress in China until recently. According to a survey conducted across 310 hospitals in 2009 by $\mathrm{Hu}$ et al, ${ }^{11}$ except for a small number of pilot hospitals, hospital pharmacists still play a role in the conventional tasks of compounding and distributing medicines, meaning that the majority of patient-centred medication-related services were provided by physicians and nurses in urban tertiary hospitals. ${ }^{12}$ Hence, in the context of the Chinese healthcare system, the barriers to encourage hospital pharmacists to provide CPSs are more complex and multifactorial.

However, the Chinese hospital pharmacists' intention to provide CPSs and impact of their beliefs and attitude towards CPSs are largely unknown. In current literature on implementation of CPSs in China, there is an absence of a theoretically grounded framework. Moreover, until now, few works of quantitative research have been focused on factors that affect establishment of CPSs in Chinese hospitals from pharmacists' perspective.
In one of the few instances of using a theory to investigate major factors affecting implementation of CPSs in China, Penm et $a l^{13}$ used the organisational model to qualitatively identify the barriers to and facilitators of implementation of CPSs in China.

Psychosocial models may be helpful in identifying key determinants of individuals' volitional behaviour. Evidence from previous research suggests that attitudes and self-efficacy may be crucial predictors of practice change among medical personnel. ${ }^{14-16}$ The results indicated that performing patient-centred services is associated with several psychosocial factors, such as the pharmacist having or developing the confidence (selfefficacy) and perceived control to provide CPSs. The provision of CPSs by a hospital pharmacist, therefore, appears to be a volitional behaviour that is influenced by the pharmacist's perception of CPSs. As such, it might be usefully understood through psychosocial models of behaviour. Several of these models of behaviour have been used to investigate barriers to the implementation of medical practice or health behaviour change, including the theory of goal-oriented behaviours and the transtheoretical model of behaviour change. ${ }^{17} 18$

The theory of planned behaviour (TPB), shown in figure 1, is one such well-established theoretical model, which predicts volitional behavioural intention in terms of the individuals' perceptions of behaviour. According to TPB, an individual's actual behaviour is influenced primarily by his/her favourable or unfavourable perception of performing the behaviour (attitude towards the behaviour, $\mathrm{AB}$ ), his/her perception of whether people important to him/her think the behaviour should be performed (subjective norms (SNs)), his/her perception of ease or difficulty of performing the behaviour (perceived behavioural control (PBC)) and his/her plan to perform behaviour (intention). ${ }^{19}$

In clinical pharmacy area, the TPB has been widely used to explore major factors associated with

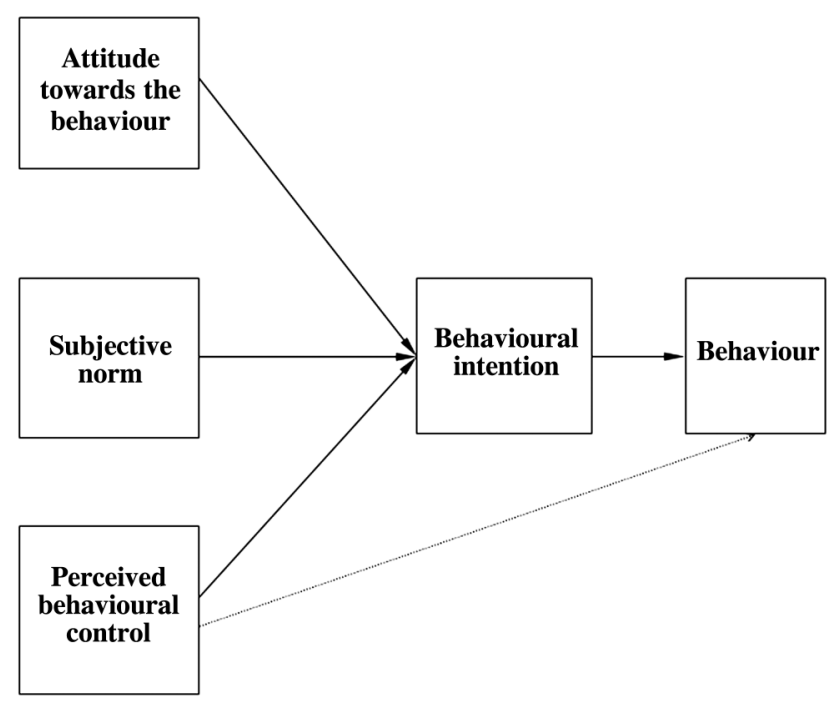

Figure 1 A framework of the theory of planned behaviour. 
pharmacists' intention to undertake a number of clinical services, including community pharmacists' intentions to provide medication-related services, ${ }^{20}{ }^{21}$ to engage in paediatric asthma counselling ${ }^{22}$ and to help patients treat vaginal candidiasis with non-prescription medicines. ${ }^{23}$ The model has also been used in a wide range of contexts to predict pharmacists' other clinical behaviours, including predicting the intentions to report serious adverse drug events among Texas pharmacists, ${ }^{24}$ examining the attitudes towards reporting medication safety incidents among British hospital pharmacists ${ }^{25}$ and measuring the intentions to use a prescription drug monitoring program (PDMP) among Virginia and Texas community pharmacists. ${ }^{26}{ }^{27}$ In these studies, the TPB was found to explain intention well and to be a good framework to measure intention across pharmacists' clinical behaviours. In addition, the TPB is one of the most thoroughly tested and robust of the psychosocial models. ${ }^{28}$ Therefore, the TPB is a promising framework to understand the predictors of hospital pharmacists' intention and behaviours within Chinese hospital pharmacy practice and was used as the guiding theoretical framework in this study.

\section{Research model and hypotheses}

This study focused on the direct measures of the TPB and their effect on intention. Based on the TPB as a framework, a research model was developed to investigate factors influencing the hospital pharmacists' behavioural intention to provide CPSs. The proposed research model is depicted in figure 2 and the study hypotheses are as follows:

H1a: Favourable attitude (A) is a positive and significant predictor of intention to provide auxiliary CPSs.
H1b: Favourable attitude (A) is a positive and significant predictor of intention to provide core CPSs.

$H 2 a$ : Strong perceived behaviour control (PBC) is a positive and significant predictor of intention to provide auxiliary CPSs.

$H 2 b$ : Strong perceived behaviour control (PBC) is a positive and significant predictor of intention to provide core CPSs.

H3a: Subjective norm ( $\mathrm{SN})$ is a positive and significant predictor of intention to provide auxiliary CPSs.

$H 3 b$ : Subjective norm ( $\mathrm{SN}$ ) is a positive and significant predictor of intention to provide core CPSs.

According to the TPB, attitudes, SN and PBC are assumed to be predictable from an individual's perception of the behaviour. Thus, hospital pharmacists' attitudes, their perceptions of the beliefs of significant others on their clinical behaviour (eg, physicians, other pharmacists, patients and hospital administrators) and their perceived control over their behaviour regarding provision of patient-centred services may influence their intentions to provide CPSs. In other words, pharmacists who have a positive attitude towards CPSs, who believe that people important to them will approve of them providing and who perceive that CPSs are under their control are more likely to intend to provide and subsequently provide.

Considering the status quo of CPSs in China, CPSs were divided into two categories in this study: core CPSs and auxiliary CPSs. According to the Basel Statements developed by the International Pharmaceutical Federation (FIP), a core element of clinical pharmacy in developed and developing countries is to influence rational prescribing and promote quality use of medicines. ${ }^{29}$ As an example, statement 29 states 'Hospital
Figure 2 Research model of pharmacists' intention to provide clinical pharmacy services based on TPB. INTA, intention to provide auxiliary clinical pharmacy services; INTC, intention to provide core clinical pharmacy services; $\mathrm{PB}$, past behaviours related clinical pharmacy services; PBC, perceived behavioural control; $\mathrm{SN}$, subjective norm; TPB, theory of planned behaviour.

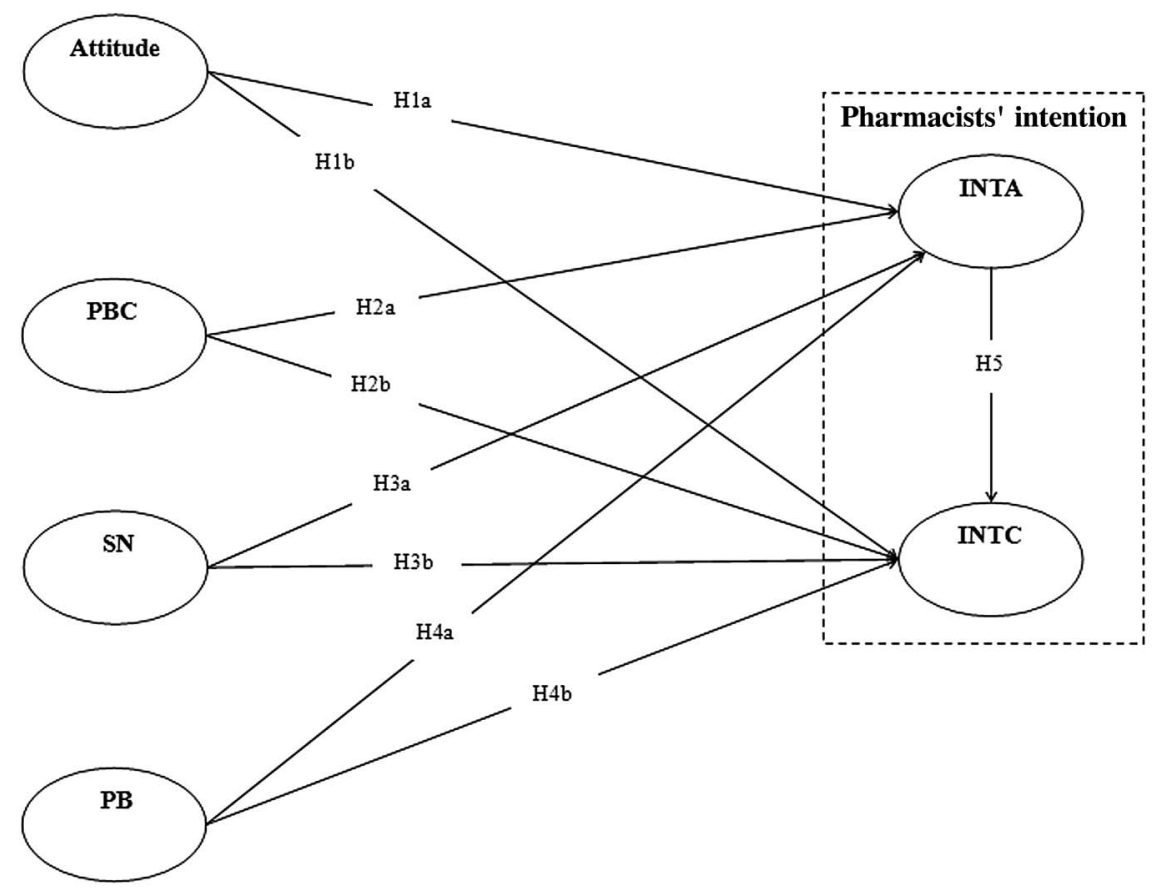


pharmacists should be involved in all patient care areas to prospectively influence collaborative therapeutic decision making'. ${ }^{29}$ Thus, the core CPSs should focus on hospital pharmacists' support of physicians' decisions in medication therapy. Making decisions means that hospital pharmacists should make suggestions for physicians to promote the rational choice of drugs, the accuracy of the dose or the appropriate duration of pharmacotherapy. However, implementation of clinical pharmacy is in its infancy in China.$^{30}$ For instance, in most urban hospitals, the major tasks of clinical pharmacists in CPSs are auxiliary, providing adverse drug reaction (ADR) monitoring, therapeutic drug monitoring and drug information counselling. ${ }^{30}$ Furthermore, $\mathrm{Hu}$ et $a l^{11}$ reported only $2 \%$ of clinical pharmacists in China actively gave advice to doctors and $12 \%$ never communicated with doctors at all. It could be indicative of the fact that there are differences between core CPSs and auxiliary CPSs intentions among the Chinese hospital pharmacists. Thus, in order to distinguish the effects of three key TPB variables on two types of CPSs and analyse the relationship of two types of CPSs intention, the investigated behavioural intention in the research model is to provide core CPSs and auxiliary CPSs by Chinese hospital pharmacists. Therefore, we posit the hypotheses related to attitude towards CPSs, SNs towards CPSs and PBC.

H4a: The past behaviours (PBs) related CPSs is a positive and significant intention to provide auxiliary CPSs.

H4b: The past behaviours (PBs) related CPSs is a positive and significant intention to provide core CPSs.

Theories of human behaviour hold that the best predictor of behavioural intention and future actual behaviour is the frequency of past relevant behaviour. The literature also shows that the predictive power of the TPB can be improved by adding other variables such as PB. For instance, Quellette and Wood found that the variance in explaining behavioural intention increased when PB was added into the TPB model ${ }^{31}$ One of the possible reasons is that people tend to maintain behavioural persistency and value consistency. In addition, PB as a 'background influence' variable was recently added in the updated TPB model. ${ }^{32}$ Thus, in addition to the three key TPB constructs (attitude, SN and PBC), PB construct was also included the research model. Consequently, PB-related CPSs may have an effect on a pharmacists' behavioural intention to provide CPSs.

H5: The hospital pharmacists' intention to provide auxiliary CPSs has a positive and significant relationship with their intention to provide core CPSs.

In the USA, hospital pharmacists took decades to move from an advisory role to taking responsibility for patient outcomes. ${ }^{33}$ Similarly, the current clinical pharmacy is at an early stage of development in China. As TPB describes, a favourable or unfavourable attitude is directly influenced by the strength of the behaviour and beliefs regarding the likely outcome. ${ }^{19}$ Most components of CPSs in Chinese hospitals are confined to auxiliary work, which promote the pharmacists to perceive of the outcome of auxiliary CPSs and have positive influence on their intention to provide auxiliary CPSs. However, the US experience of CPSs indicates auxiliary CPSs and core CPSs are at different stages of development. It predicates that the Chinese hospital pharmacists' intention to provide auxiliary CPSs will be translated to actual behaviour and evolved into intention to provide core CPSs in the near future. In other words, although provision of core CPSs by hospital pharmacists is hindered by various external and internal factors, there is still a huge possibility that a pharmacist who has a comparatively strong intent to provide auxiliary CPSs shows more willingness to involve in core CPSs. Thus, we can posit that the pharmacists' intention to provide auxiliary CPSs will have a significant impact on their intention to provide core CPSs.

\section{Aims}

The aim of this study was to explore the usefulness of the TPB model in predicting Chinese hospital pharmacists' intention to provide CPSs, including auxiliary CPSs and core CPSs. The focus of this study was to identify the main factors affecting the pharmacists' intention to provide core CPSs based on TPB quantitatively, which will provide evidence for improving management strategy.

\section{METHODS}

\section{Development of the survey instrument}

A cross-sectional survey using the TPB was conducted to test the hypotheses. The questionnaire used for data collection contained scales to measure the various constructs of the research models. A self-administered questionnaire was designed on the basis of information regarding CPSs in Chinese hospitals obtained from previous qualitative interviews and current literature. The authors of this paper conducted the interviews. The aims of the interviews were to form research hypotheses based on the TPB and elicit hospital pharmacists' beliefs regarding CPSs. Each interview lasted about $20 \mathrm{~min}$. A moderator guide based on the TPB was used to identify participants' beliefs about CPSs. Participants were also asked additional questions to explore other possible affecting factors (general views on CPSs provided by hospital pharmacists, importance of CPSs, skill and knowledge of pharmacists, influence of hospital administration) that may influence pharmacists' intentions to provide CPSs.

After the pretest and reasonable adjustment to the questionnaire measures, a formal questionnaire for study was formed. The questionnaire was pretested with 10 hospital pharmacists with varied ages, work roles, education levels and experiences to ensure content validity, face validity and clarity of all questions. Comments from the pretest group were evaluated and minor changes were then made to the wording of a number of questions. Based on feedback from hospital pharmacists regarding CPSs, we revised two items to assess pharmacists' SN scale and added an additional question to assess pharmacists' PBC scale. 
The questionnaire consists of three parts: the first part contains a cover letter explaining the definition of CPSs, the main contents of CPSs and the purpose of the study; items related to the respondents' demographics and relevant characteristics, including gender, education level, years of practice in hospital and current position; and 27 items were generated on the basis of the 6 main constructs of the TPB including the attitude of pharmacists towards CPSs (six items), SNs (four items), pharmacists' PBC (three items), PB-related CPSs (five items), behavioural intention to provide auxiliary CPSs (six items) and behavioural intention to provide core CPSs (three items).

The items in the intent and PB scales were worded as specific components of CPSs, rather than global CPSs. In contrast, the items in other scales were worded as globally. This was done because we attempted to assess the hospital pharmacists' perception of overall CPSs in key TPB variables (attitude, SN, PBC). Except the PB scale, the other items were scored on a 5-point Likert scale with possible answers being strongly disagree, disagree, neutral, agree and strongly agree. The items of PB scale were scored on a 5-point Likert scale. Scale anchors ranged from never (1) to rarely (2), occasionally (3), often (4) and frequently (5). The English questionnaire was translated to Chinese and back translated to English. The semantic equivalence of the two questionnaires was confirmed by two senior healthcare researchers who were fluent in English and Chinese.

\section{Sample and data collection}

In the survey, the Chinese hospital pharmacists were sampled through the multistage random stratified sampling. In the first sample stage, seven cities were selected based on geographic location and economic characteristics from the eastern and western parts of China, respectively. In the next stage, three or four urban general hospitals in each city were selected from the sample hospital list, based on size, grade and hospital beds. In the third stage, 20 pharmacists were randomly selected in each hospital. All in all, 440 hospital pharmacists were enrolled from 22 urban general hospitals in 2 municipalities (4 hospitals in Beijing and 3 in Shanghai) and 5 provincial capitals ( 3 hospitals in Nanjing, 3 in Hangzhou, 3 in Jinan, 3 in Kunming and 3 in Xi'an). The categories of these hospitals included tertiary hospital A, tertiary hospital B and secondary hospital. All of the hospitals are located in the urban areas, with an average of 2000 beds. In China, the implementation of CPSs is a top-down institutionally driven by health authorities, which means that the intentions to provide CPSs among the pharmacists in these sampled urban large hospitals have certain representativeness in China. According to the regulations that are issued by NHFPC, the urban hospitals should employ a minimum of five clinical pharmacists. With the development of CPSs in China, the number of clinical pharmacist in urban general hospitals increases gradually. In this study, based on available data, it appeared that an average of 20 clinical pharmacists and 40 non-clinical pharmacists worked in the department of pharmacy at the 22 sampled hospitals. Considering the clinical pharmacists are major providers of CPSs, we place a higher value on the clinical pharmacists' intention than non-clinical pharmacists' intention. Therefore, 10-12 clinical pharmacists and 8-10 non-clinical pharmacists (dispensing pharmacists and others) were randomly selected from the name list that was provided by the administrative office of the hospital. The initial aim of this survey was to complete 20 questionnaires in each hospital, with a goal of 440 respondents in total.

After getting permission from the administrative office of the hospital, two well-trained research assistants (RAs) in each hospital administered the questionnaires in the pharmacists' office in person between June and October 2013. The pharmacists were randomly selected from the name list that was provided by the administrative office of the hospital. The RAs distributed the questionnaires to the potential participants by hand and waited for their completion. The RAs first described the purpose of the study and then asked whether the pharmacists were willing to participate. After giving verbal consent, the participants completed the questionnaires. The participants were required to independently finish the questionnaires. Meanwhile, in order to ensure the independence and anonymity of the survey, the RAs were required to wait for completion of the questionnaires outside the hospital pharmacists' offices. Finally, the RAs checked the questionnaires that had been completed to avoid mistakes and missing items.

\section{Data analysis and statistics}

Data were entered using Microsoft Excel. Descriptive statistics including frequencies, means and SDs for each item on the questionnaire were calculated using SPSS V.17.0 (SPSS, Chicago, Illinois, USA).

The statements were dichotomised to simplify calculations for the percentage of respondents. Ratings of one or two (strongly disagree to disagree and never to rarely, respectively) were considered negative or low frequent, whereas ratings of four or five (agree to strongly agree and often to frequently, respectively) were considered positive or high frequent.

Partial least squares (PLS) technique was employed to perform the analysis. PLS is a second generation structural equation modelling (SEM) technique that is designed to maximise the predicted variance in dependent variables. It places minimal restrictions on sample size and residual distributions, which is best suited for analysing complex model with latent variables and without imposing constraints on model specification and data distribution assumptions. ${ }^{34}$ Thus, it was used to accommodate the presence of relatively lean sample sizes and a large number of variables. Unlike covariancebased approaches such as LISREL and AMOS, it is a variance-based method that does not generate fit 
indices; instead, it relies on factor loadings, path weights and explained variances to estimate the model.${ }^{35}$ In this study, Smart PLS (V.2.0) was the tool used to estimate the measurement and structural models.

\section{RESULTS}

Of the 440 questionnaires distributed, 420 were returned. Among the 420 questionnaires, 416 were usable for an overall response rate of $94.55 \%$. The reasons for unreturned or unusable questionnaire were as follows: the pharmacists refused to complete questionnaire and the respondents did not complete all of the items.

The participating pharmacists' demographics and relevant characteristics are shown in table 1 . Among the respondents, $292(70.2 \%)$ were female pharmacists and $397(95.4 \%)$ worked in the tertiary hospitals. Approximately two-fifths of the respondents had Master's or Doctoral degrees $(36.8 \%)$, and more than half of respondents were clinical pharmacists $(53.4 \%)$. Many respondents were junior pharmacist $(40.3 \%)$ and pharmacist-in-charge $(40.1 \%)$. A majority had been working in hospital for 10 years or less $(59.9 \%)$.

Table 2 lists the dichotomisation of the scale of individual items including the percentage of respondents rating positive versus negative for each statement on attitude, SN, PBC and intent scale. It also lists descriptive statistics for individual items including the percentage of respondents rating high frequent versus low frequent for each statement on PB scale. In terms of attitudes towards CPSs, pharmacists tended to agree that

\begin{tabular}{llc}
\multicolumn{3}{l}{$\begin{array}{l}\text { Table 1 Demographics and relevant characteristics of } \\
\text { participants }(\mathrm{n}=416)\end{array}$} \\
\hline The variables & Values & $\mathbf{n}(\%)$ \\
\hline Gender & Male & $124(29.8)$ \\
& Female & $292(70.2)$ \\
Years of & 3 or less & $104(25.0)$ \\
practice & $4-10$ & $145(34.9)$ \\
& $11-20$ & $97(23.3)$ \\
Education level & $70(16.8)$ \\
& $>20$ & $263(63.2)$ \\
& Bachelor's degree and & \\
& below & $134(32.2)$ \\
Current position & $19(4.6)$ \\
& Master's degree & $168(40.3)$ \\
& Doctoral degree & $167(40.1)$ \\
& Junior pharmacist & $65(15.6)$ \\
Types of & Pharmacist-in-charge & $16(3.8)$ \\
hospital & Deputy chief pharmacist & $377(90.6)$ \\
& Chief pharmacist & $20(4.8)$ \\
Work role & Tertiary hospital class A & $19(4.6)$ \\
& Tertiary hospital class B & $222(53.4)$ \\
& Secondary hospital & $160(38.5)$ \\
& Clinical Pharmacist & $34(8.1)$ \\
\hline
\end{tabular}

providing CPSs could help physicians to avoid medication errors, enhance the safety of drug use effectively, promote the level of rational uses of drugs and optimise the efficacy of medication. They were less likely to agree that providing CPSs would reduce the drug costs and enhance the economics of medication effectively. While, almost $80 \%$ of the respondents agreed that involvement in CPSs will improve their job satisfaction and achievability of work.

For the construct $\mathrm{SN}$, the respondents were somewhat more likely to agree that most people who are important to them would approve of them providing CPSs than they were to agree that patients and pharmacists would approve of them providing CPSs. However, only 43.3\% agreed and strongly agreed that physicians in their hospitals would like to support them providing CPSs.

For PBC, more pharmacists agreed that regulations and management model of their hospital are enough to support them participating in CPSs than agreed that they had the necessary knowledge, skills and hardware support to provide CPSs.

The frequency of pharmacists' involvement in CPSs in the previous 12 months was generally low. The mean scores for the all five items measuring $\mathrm{PB}$ relating patient-centred services were below three. Almost threefifths $(56.3 \%)$ of the respondents had never or rarely implemented pharmaceutical care for hospitalised patients and $51.4 \%$ had never or rarely involved in physicians' ward rounds to make suggestions for drug therapy plans for patients. Only $47.8 \%$ of pharmacists indicated that they had often or frequently checked the prescription to detect and prevent prescription errors.

Overall, the pharmacists showed stronger intent to provide auxiliary CPSs. The mean scores for the six items measuring intent to provide auxiliary CPSs were $4.16 \pm 0.69,4.15 \pm 0.70,4.14 \pm 0.73,3.85 \pm 0.88,4.29 \pm 0.60$ and $4.12 \pm 0.77$. A total of $93.5 \%$ of respondents agreed or strongly agreed that they intended to counsel patients regarding the safe and appropriate use of their medications and provide patient education, and $88.3 \%$ agreed or strongly agreed that they planned to involve in implementing therapeutic drug monitoring. Compared with auxiliary CPSs, the level of pharmacists' intention to provide core CPSs was relatively low. The mean scores for the three items assessing intention to provide core CPSs were $3.94 \pm 0.92,3.87 \pm 1.10,3.86 \pm 0.94$. In total, $78.3 \%$ agreed or strongly agreed that they intent to involve in physicians' ward rounds to make suggestions for drug therapy plans for patients and share the responsibilities for medication with physicians.

Since the measures were self-developed, we evaluated the measures to confirm their reliability and validity before testing the research model. The correlations, reliabilities and average variance extracted (AVE) are reported in table 3 . The results provide evidence of the reliability and validity of the measures. First, all multiitem scales have high Cronbach's $\alpha$ coefficients $(>0.70)$, showing satisfactory reliability. Second, as table 4 shows, 
Table 2 Survey statements and descriptive statistics by conduct $(n=416)$

\begin{tabular}{|c|c|c|c|c|}
\hline Construct & Survey statement & Mean \pm SD & $\begin{array}{l}\text { Positive/high } \\
\text { frequent }(n, \%)\end{array}$ & $\begin{array}{l}\text { Negative/low } \\
\text { frequent }(n, \%)\end{array}$ \\
\hline \multirow[t]{6}{*}{ Attitude } & $\begin{array}{l}\text { CPSs provided by hospital pharmacists can help } \\
\text { physicians to avoid medication errors and enhance the } \\
\text { safety of drug use effectively }\end{array}$ & $4.42 \pm 0.65$ & $382(91.8)$ & $1(0.2)$ \\
\hline & $\begin{array}{l}\text { CPSs provided by hospital pharmacists can promote the } \\
\text { level of rational uses of drugs and optimise the efficacy of } \\
\text { medication }\end{array}$ & $4.35 \pm 0.67$ & 377 (90.7) & $3(0.7)$ \\
\hline & $\begin{array}{l}\text { CPSs provided by hospital pharmacists can reduce the } \\
\text { drug costs and enhance the economics of medication } \\
\text { effectively }\end{array}$ & $3.87 \pm 0.90$ & $233(56.1)$ & $25(6.0)$ \\
\hline & $\begin{array}{l}\text { CPSs provided by hospital pharmacists can promote the } \\
\text { quality of medical services effectively }\end{array}$ & $4.22 \pm 0.73$ & $320(77.0)$ & $9(2.2)$ \\
\hline & Participation in CPSs will improve my achievability of work & $4.10 \pm 0.85$ & $332(79.8)$ & $15(3.6)$ \\
\hline & Participation in CPSs will improve my job satisfaction & $3.97 \pm 0.80$ & 317 (76.2) & $13(3.1)$ \\
\hline \multirow[t]{4}{*}{ SN } & $\begin{array}{l}\text { Most people who are important to me approve of me } \\
\text { providing CPSs }\end{array}$ & $3.75 \pm 1.05$ & $285(68.5)$ & $37(8.9)$ \\
\hline & $\begin{array}{l}\text { Physicians in our hospital would approve of me providing } \\
\text { CPSs }\end{array}$ & $3.27 \pm 0.97$ & $180(43.3)$ & $69(16.6)$ \\
\hline & Patients in our hospital would like to see me provide CPSs & $3.27 \pm 0.98$ & $188(45.2)$ & $69(16.6)$ \\
\hline & $\begin{array}{l}\text { Pharmacists whose opinions I value in our hospital would } \\
\text { like to approve of me providing CPSs }\end{array}$ & $3.25 \pm 1.05$ & $189(45.4)$ & $64(15.4)$ \\
\hline \multirow[t]{3}{*}{ PBC } & $\begin{array}{l}\text { I think I have necessary knowledge and skills to provide } \\
\text { CPSs }\end{array}$ & $3.46 \pm 0.92$ & $214(51.5)$ & $56(13.5)$ \\
\hline & $\begin{array}{l}\text { Pharmacists in our hospital have necessary hardware and } \\
\text { software support to provide CPSs }\end{array}$ & $3.33 \pm 1.10$ & $206(49.6)$ & $88(21.2)$ \\
\hline & $\begin{array}{l}\text { Regulations and management model of our hospital are } \\
\text { enough to support me participating in CPSs }\end{array}$ & $3.49 \pm 0.99$ & $230(55.3)$ & $50(12.0)$ \\
\hline \multirow[t]{5}{*}{ PB } & $\begin{array}{l}\text { Involving in physicians' ward rounds to make suggestions } \\
\text { for drug-therapy plans for patients }\end{array}$ & $2.55 \pm 1.55$ & $145(34.9)$ & $214(51.4)$ \\
\hline & Implementing pharmaceutical care for hospitalized patients & $2.50 \pm 1.57$ & $139(33.4)$ & $234(56.3)$ \\
\hline & $\begin{array}{l}\text { Reviewing the prescription to detect and prevent } \\
\text { prescription errors }\end{array}$ & $2.98 \pm 1.60$ & $199(47.8)$ & $173(41.6)$ \\
\hline & Writing medication records for hospitalized patients & $2.57 \pm 1.57$ & $155(37.2)$ & $222(53.4)$ \\
\hline & $\begin{array}{l}\text { Assisting physicians in monitoring the hospitalized patients' } \\
\text { ADRs }\end{array}$ & $2.98 \pm 1.52$ & $182(43.8)$ & 165 (39.7) \\
\hline \multirow[t]{6}{*}{ INTA } & $\begin{array}{l}\text { I intend to review prescription or medical order record to } \\
\text { detect and prevent prescription errors }\end{array}$ & $4.16 \pm 0.69$ & $359(86.3)$ & $5(1.2)$ \\
\hline & $\begin{array}{l}\text { If necessary, I intent to involve in implementing therapeutic } \\
\text { drug monitoring }\end{array}$ & $4.15 \pm 0.70$ & $367(88.3)$ & $7(1.7)$ \\
\hline & $\begin{array}{l}\text { I will explain the results of therapeutic drug monitoring to } \\
\text { the patients }\end{array}$ & $4.14 \pm 0.73$ & $363(87.2)$ & $9(2.2)$ \\
\hline & I intent to write medication records for hospitalized patients & $3.85 \pm 0.88$ & $304(73.1)$ & $31(7.5)$ \\
\hline & $\begin{array}{l}\text { I intent to counsel patients regarding the safe and } \\
\text { appropriate use of their medications and provide patient } \\
\text { education }\end{array}$ & $4.29 \pm 0.60$ & $389(93.5)$ & $2(0.5)$ \\
\hline & $\begin{array}{l}\text { I intent to implement pharmaceutical care for hospitalized } \\
\text { patients }\end{array}$ & $4.12 \pm 0.77$ & $358(86.1)$ & $14(3.4)$ \\
\hline \multirow[t]{3}{*}{ INTC } & $\begin{array}{l}\text { I intent to involve in physicians' ward rounds to make } \\
\text { suggestions for drug-therapy plans for patients and share } \\
\text { the responsibilities for medication with physicians }\end{array}$ & $3.94 \pm 0.92$ & $325(78.1)$ & $33(7.9)$ \\
\hline & $\begin{array}{l}\text { I intent to involve in physicians' case discussions to make } \\
\text { suggestions for drug-therapy plans for patients and share } \\
\text { the responsibilities for medication with physicians }\end{array}$ & $3.87 \pm 0.94$ & $31(75.3)$ & $37(8.9)$ \\
\hline & $\begin{array}{l}\text { I intent to involve in physicians' consultation to make } \\
\text { suggestions for drug-therapy plans for patients and share } \\
\text { the responsibilities for medication with physicians }\end{array}$ & $3.86 \pm 0.94$ & 314 (75.5) & $38(9.1)$ \\
\hline
\end{tabular}

ADR, adverse drug reaction; CPS, clinical pharmacy service; INTA, intention to provide auxiliary clinical pharmacy services; INTC, intention to provide core clinical pharmacy services; PB, past behaviours related clinical pharmacy services; PBC, perceived behavioural control; SN, subjective norm. 
Table 3 Correlations among variables

\begin{tabular}{llllllllll}
\hline & R & AVE & CR & PB & A & INTA & INTC & PBC & SN \\
\hline PB & 0.91 & 0.74 & 0.93 & $\mathbf{0 . 8 6}$ & & & & & \\
A & 0.88 & 0.63 & 0.91 & 0.12 & $\mathbf{0 . 7 9}$ & & & & \\
INTA & 0.89 & 0.64 & 0.92 & 0.22 & 0.40 & $\mathbf{0 . 8 0}$ & & & \\
INTC & 0.93 & 0.88 & 0.96 & 0.23 & 0.42 & 0.71 & $\mathbf{0 . 9 4}$ & & \\
PBC & 0.73 & 0.65 & 0.85 & 0.23 & 0.22 & 0.25 & 0.24 & $\mathbf{0 . 8 1}$ & $\mathbf{0 . 7 5}$ \\
SN & 0.73 & 0.56 & 0.83 & 0.19 & 0.37 & 0.25 & 0.31 & 0.55 &
\end{tabular}

Square roots of AVE are bolded, shown on diagonal.

A, attitudes; AVE, average variance extracted; CR, composite reliability; INTA, intention to provide auxiliary clinical pharmacy services; INTC, intention to provide core clinical pharmacy services; PB, past behaviours regarding clinical pharmacy services; PBC, perceived behavioural control; R, Cronbach's $\alpha$; SN, subjective norm.

each item has a high and significant loading on its underlying construct $(>0.70)$, showing satisfactory convergent validity. In addition, the AVEs are $>0.50$ and the square roots of each construct's AVE is greater than the cross-construct correlations, suggesting satisfactory discriminant validity.

Table 5 and figure 3 show the structural model testing results. Overall, except H2b, H3a and H4b, all of the hypotheses are supported. The coefficients, shown in figure 3, indicate that attitudes, $\mathrm{SN}$ and intention to provide auxiliary CPSs had statistically significant influence over intention to provide core CPSs. A total of 54\% of the variance in intention to provide core CPSs is explained by the three predictors. Of the three, intention to provide auxiliary CPSs had the strongest influence $(\beta=0.63)$, followed by attitude $(\beta=0.12)$ and $\mathrm{SN}$ $(\beta=0.10)$. In total, $21 \%$ of the variance in intention to provide auxiliary CPSs was accounted for by three predictors in the SEM model. The attitude, PBC and PB are all significantly related to intention to provide auxiliary CPSs, whereas SN is not. Of the three, attitude had the strongest influence $(\beta=0.35)$, followed by $\mathrm{PB}(\beta=0.15)$ and PBC $(\beta=0.12)$.

\section{DISCUSSION}

To our knowledge, this is the first known study to examine hospital pharmacists' intention to provide CPSs within the theoretical framework of the TPB in China. The study also examined the relationship between the pharmacists' intention to provide auxiliary CPSs and their intention to provide core CPSs.

As hypothesised, pharmacists' attitudes, $\mathrm{PBC}$ and $\mathrm{PB}$ were significant predictors of intention to provide auxiliary CPSs, but SN was not. While pharmacists' attitudes and $\mathrm{SN}$ were significant predictors of intention to provide core CPSs, PBC and PB were not significant predictors. In addition, the pharmacists' intention to provide auxiliary CPSs was also significant predictors of their intention to provide core CPSs. The combination of attitude, SN and intention to provide auxiliary CPSs explained 54.0\% of the variance in intention to provide core CPSs. Given the reviews of the TPB have supported its usefulness with the TPB explaining 39\% of variance in intention on

\begin{tabular}{|c|c|c|c|c|c|c|}
\hline & PB & A & INTA & INTC & PBC & SN \\
\hline PB1 & 0.81 & & & & & \\
\hline PB2 & 0.90 & & & & & \\
\hline PB3 & 0.91 & & & & & \\
\hline PB4 & 0.77 & & & & & \\
\hline PB5 & 0.90 & & & & & \\
\hline $\mathrm{A} 1$ & & 0.85 & & & & \\
\hline $\mathrm{A} 2$ & & 0.85 & & & & \\
\hline A3 & & 0.76 & & & & \\
\hline A4 & & 0.84 & & & & \\
\hline A5 & & 0.74 & & & & \\
\hline A6 & & 0.73 & & & & \\
\hline INTA1 & & & 0.84 & & & \\
\hline INTA2 & & & 0.76 & & & \\
\hline INTA3 & & & 0.80 & & & \\
\hline INTA4 & & & 0.85 & & & \\
\hline INTA5 & & & 0.75 & & & \\
\hline INTA6 & & & 0.82 & & & \\
\hline INTC1 & & & & 0.93 & & \\
\hline INTC2 & & & & 0.95 & & \\
\hline INTC3 & & & & 0.94 & & \\
\hline PBC1 & & & & & 0.89 & \\
\hline PBC2 & & & & & 0.80 & \\
\hline PBC3 & & & & & 0.72 & \\
\hline SN1 & & & & & & 0.78 \\
\hline SN2 & & & & & & 0.71 \\
\hline SN3 & & & & & & 0.76 \\
\hline SN4 & & & & & & 0.72 \\
\hline \multicolumn{7}{|c|}{$\begin{array}{l}\text { PBC1-PBC3, the three items measuring respondents' perceived } \\
\text { behavioural control; SN1-SN4: the four items measuring } \\
\text { respondents' subjective norm. } \\
\text { A1-A6, the six items measuring respondents' attitudes; PB1-PB4, } \\
\text { the four items measuring respondents' frequency of past } \\
\text { behaviours related clinical pharmacy services; INTA1-INTA6, the } \\
\text { six items measuring respondents' intention to provide auxiliary } \\
\text { clinical pharmacy services; INTC1-INTC3, the three items } \\
\text { measuring respondents' intention to provide core clinical } \\
\text { pharmacy services. } \\
\text { A, attitudes; INTA, intention to provide auxiliary clinical pharmacy } \\
\text { services; INTC, intention to provide core clinical pharmacy } \\
\text { services; PB, past behaviours related clinical pharmacy services; } \\
\text { PBC, perceived behavioural control; SN, subjective norm. }\end{array}$} \\
\hline
\end{tabular}

average ${ }^{28}$ the results were consistent with the predicted relationships among the key TPB variables (attitude, PBC, $\mathrm{SN}$ and intention). It demonstrated the TPB model could 
Table 5 Hypothesis testing results

\begin{tabular}{|c|c|c|c|c|}
\hline Hypothesis & Path & $\begin{array}{l}\text { Path } \\
\text { coefficient (ß) }\end{array}$ & t value & Result \\
\hline $\mathrm{H} 1 \mathrm{a}$ & Attitude $\rightarrow$ intention to provide auxiliary CPSs & 0.35 & 6.63 & Supported \\
\hline $\mathrm{H} 1 \mathrm{~b}$ & Attitude $\rightarrow$ intention to provide core CPSs & 0.12 & 2.67 & Supported \\
\hline $\mathrm{H} 2 \mathrm{a}$ & Perceived behaviour control $\rightarrow$ intention to provide auxiliary CPSs & 0.12 & 2.37 & Supported \\
\hline $\mathrm{H} 2 \mathrm{~b}$ & Perceived behaviour control $\rightarrow$ intention to provide core CPSs & -0.01 & 0.24 & Not supported \\
\hline H3a & Subjective norms $\rightarrow$ intention to provide auxiliary CPSs & 0.03 & 0.42 & Not supported \\
\hline $\mathrm{H} 3 \mathrm{~b}$ & Subjective norms $\rightarrow$ intention to provide core CPSs & 0.10 & 2.08 & Supported \\
\hline $\mathrm{H} 4 \mathrm{a}$ & Past behaviour $\rightarrow$ intention to provide auxiliary CPSs & 0.15 & 3.34 & Supported \\
\hline $\mathrm{H} 4 \mathrm{~b}$ & Past behaviour $\rightarrow$ intention to provide core CPSs & 0.06 & 1.75 & Not supported \\
\hline H5 & Intention to provide auxiliary CPSs $\rightarrow$ intention to provide core CPSs & 0.63 & 15.61 & Supported \\
\hline
\end{tabular}

Figure 3 Path diagram for research model. INTA, intention to provide auxiliary clinical pharmacy services; INTC, intention to provide core clinical pharmacy services; PB, past behaviours related clinical pharmacy services; PBC, perceived behavioural control; $\mathrm{SN}$, subjective norm.

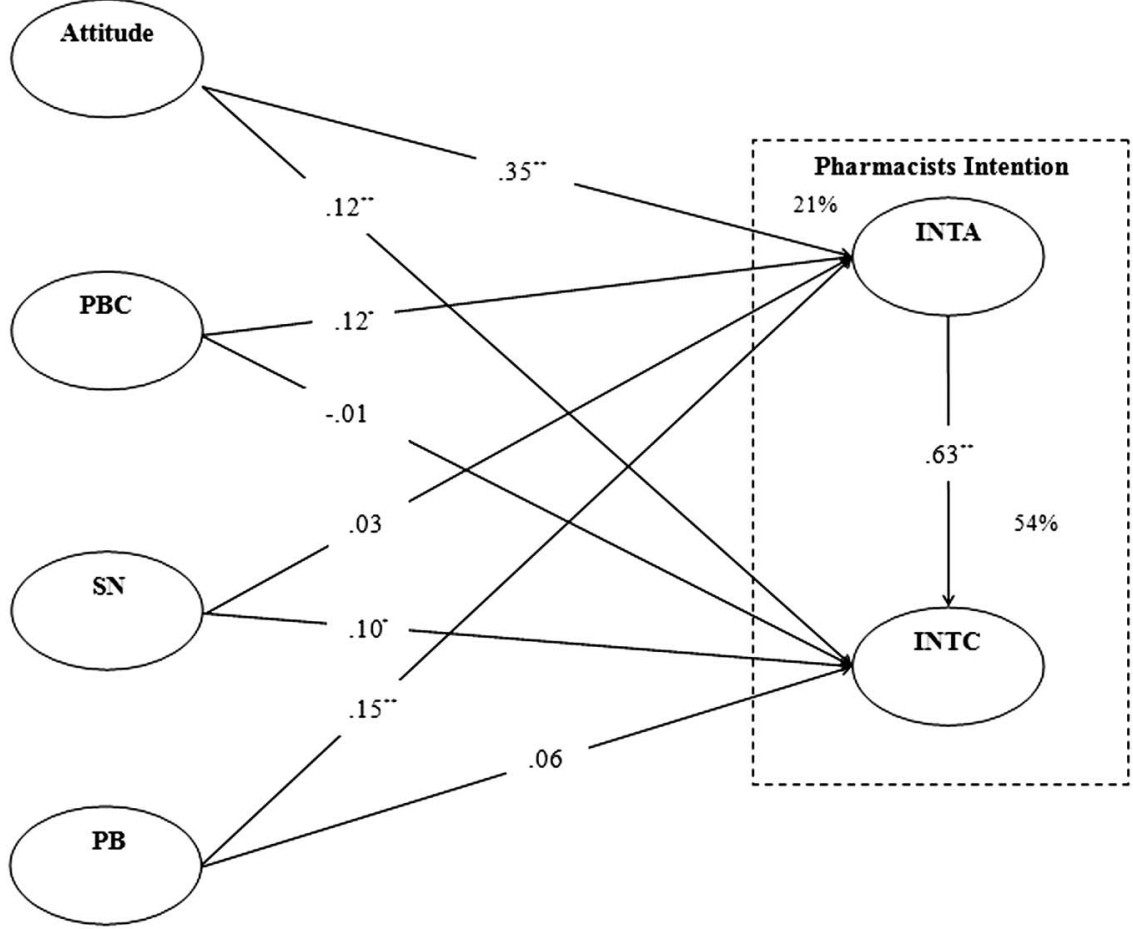

Note: ${ }^{*} \mathrm{P}<.05 ; * * \mathrm{P}<.01$; be well suited to better understanding hospital pharmacists' intentions to provide CPSs.

In general, the sampled hospital pharmacist showed strong intention to provide auxiliary CPSs and moderate intention to provide core CPSs, respectively. This finding is in line with previous studies based on TPB in developed countries that found that pharmacists had high intentions to provide medication-related services. ${ }^{20} 21$ For instance, Herbert et $a l^{21}$ found that community pharmacist expressed positive and strong intents to provide medication therapy management services (MTMS). ${ }^{21}$ Nevertheless, it is noteworthy that the results seem to indicate the existence of inconsistency between intention and self-reported actual behaviour. The respondents were found to have high intentions to provide CPSs, but a low amount of CPSs was actually performed. For instance, in this study, $78.1 \%$ of respondents agreed and strongly agreed that they intent to involve in physicians' ward rounds to make suggestions for drug therapy plans for patients and share the responsibilities for medication with physicians. In contrast, only $34.9 \%$ reported they had often or frequently involved in physicians' ward rounds to make suggestions for drug therapy plans for patients. While $86.1 \%$ had intention to implement pharmaceutical care for hospitalised patients, only $33.4 \%$ reported they had often or frequently implemented it. Importantly, this finding shows that a significant percentage of respondents were not fully engaged in the communication with physicians about therapeutic options and making suggestions on rational drug use, 
despite them having favourable intention. This finding is similar to previous studies conducted in the USA. ${ }^{21} 22{ }^{24}$ Moreover, when compared with the results of survey conducted in developed countries, the frequency of self-reported PBs regarding core CPSs looked much lower. According to the results of the 2012 national survey of pharmacy practice in the USA, pharmacists most commonly provided suggestions to prescribers for dosage adjustment (98.3\%), drug information $(93.2 \%)$ and recommendations for antibiotic therapy $(91.7 \%) .{ }^{36}$ Based on findings of the study, we can conclude that the translation of pharmacists' intentions into actual behaviours, especially for behaviours regarding core CPSs, is impeded or moderated by several factors. The factors which may explain the inconsistency between intention and behaviour were proven to include perceptions of the efficacy and costs of the behaviour, low perceived social norm by physicians, low PBC, low self-efficacy (ie, how confident a pharmacist is that he/she will successfully provide CPSs) and frequency of behaviour performance. ${ }^{24}$ 37-39

In the present study, attitude is a pharmacist's favourable or unfavourable perception of CPSs in question. Generally, the survey results show that pharmacists expressed positive and strong attitudes towards CPSs. Attitude was the strongest predictor of intention to provide auxiliary CPSs after controlling for PBC, SN and $\mathrm{PB}$. Meanwhile, it was also important predictor of intention to provide core CPSs. Previous studies also found that pharmacists had positive attitudes towards medication-related services. ${ }^{20-22}$ In addition, some scholars argued that attitudes towards the behaviour are the best predictors of intention in the TPB model. ${ }^{28}{ }^{40}$ This study supports the finding that attitude was a significant and positive predictor of pharmacists' high intentions and extends the finding to the CPSs in China's healthcare contexts. However, only $56.1 \%$ of respondents thought that CPSs can reduce the drug costs and enhance the economics of medication effectively. It shows that while respondents think that CPSs are favourable, there is still room for improving their attitude towards CPSs. Taken together, these findings show that attitude is an important antecedent for pharmacists' intentions and should be targeted in interventions aimed at promoting hospital pharmacists to provide CPSs.

The study results also confirm the influence of PBC on pharmacists' intention to provide auxiliary CPSs, but PBC was not a significant predictor of intention to provide core CPSs. Similarly, in previous studies assessing direct effect of PBC on intention, the results have been mixed. $\mathrm{PBC}$ was not found to be a significant predictor of intention to report serious adverse drug events to the FDA. ${ }^{24}$ Contrarily, Herbert et $a l^{21}$ and Pradel et $a l^{22}$ found PBC to be a significant and positive predictor of intention to provide MTMS and asthma counselling, respectively; but Gavaza $e t a l^{26}$ found $\mathrm{PBC}$ to be a significant and negative predictor of intention to use PDMP.
Coincidentally, the effect of PBC on predicting pharmacists' intentions was partly supported by the current study.

Several possible factors could be proposed to explain this finding in this study. Based on different type of CPSs, the control factors that may facilitate or hinder the pharmacists' performance of the behaviours regarding CPSs are somewhat different. The pharmacists' knowledge and skill, and regulations of hospitals can play a major role in formulation of their confidence in core CPSs such as participating in physicians' ward rounds, consultations, case discussions and making suggestions on drug use, on the other hand, hardware and software support are more important than former in formulation of pharmacists' intention to provide auxiliary CPSs. In this study, only $13.5 \%$ of respondents thought that they don't have necessary knowledge and skills to provide CPSs and 12\% thought the hospital's regulations and management model are not enough to support them participating in CPSs. Meanwhile, 21.2\% thought they don't have necessary hardware and software supports to provide CPSs. In addition, almost half of the respondents believed that they were confident that they had necessary knowledge and skills to provide CPSs. Thus, it is inferred that the respondents perceived more about the presence of factors that hinder the behaviour regarding auxiliary CPSs. That is one likely reason why the PBC construct had contributed to non-significance in pharmacists' intention to provide core CPSs. This implies that implementation of auxiliary CPSs should be focused on the hospital's environment rather than on the necessary clinical skills. However, it is noteworthy that these results are from self-reported surveys and may not be an objective representation of the respondents' knowledge and skills. Certainly, it is still crucial for the health authorities to ensure that hospital pharmacists are well trained and facilitate the development of substantial PBC towards the provision of core CPSs among them.

$\mathrm{SN}$, which refers to the perceived social pressure to perform or not to perform the behaviour in question, was a significant TPB predictor of intention to provide core CPSs. This concurs with findings from previous studies on pharmacists' behaviours in developed countries. $^{20-27}$ Similarly, other studies on pharmacists' behaviours in clinical services setting found that $\mathrm{SN}$ was the most important predictor of intention. ${ }^{21}$ Moreover, Quine $e t a l^{41}$ argued that $\mathrm{SN}$ is of greater importance in the formation of intention regarding a behaviour that carries implications for others. Thus, the role of SN in the formulation of intentions may be explained by the fact that providing core CPSs is perceived to have implications for other important individuals or groups such as physicians, patients, hospital administrators and colleagues.

However, SN was not a significant predictor of intention to provide auxiliary CPSs. One possible reason is that the characteristic of auxiliary CPSs is similar with 
the traditional tasks of a hospital pharmacist (eg. compounding and dispensing of medications). Given that hospital pharmacists do not need to exert their influence on rational prescribing in auxiliary CPSs and change their auxiliary role in hospital, the important individuals in hospital settings such as physicians and patients will never change their opinion regarding pharmacists' activities. Thus, the pharmacists usually believe that other important individuals would wish them to perform the auxiliary CPSs as well as to perform dispensing of medications. Based on above findings, it may be useful to develop management strategies that influence pharmacists' $\mathrm{SN}$ as it relates to provision of core CPSs.

Similar to PBC in this study, this PB construct was found to be a significant predictor of intention to provide auxiliary CPSs, but not a significant predictor of intention to provide core CPSs. One of the reasons could be that three-fifths of the items used to measure the PB construct are related to auxiliary CPSs. It makes the PB construct has more relevance with respondents' intention to provide auxiliary CPSs. In addition, more than half of the respondents had never or rarely involved core CPSs, which indicates that they lack of practiced experiences with core CPSs and had no idea of the likely outcomes of core CPSs. Despite this, this result partly supports the similar findings had been reported in the literature: the PB could significantly influence pharmacists' intention to perform health-related behaviours. ${ }^{24}$ Taken together, these findings indicate that $\mathrm{PB}$ is an important predictor and, thus, should be included in models of health-related behaviours intentions among Chinese hospital pharmacists. Moreover, the salient implication can be derived from this result is that providing pharmacists who have never involved in patient-centred clinical services with real experiences may significantly increase their intentions to provide CPSs in the future. Furthermore, interventions to improve the level of pharmacists' participations in core CPSs should focus on those who have not involved in core activities of CPSs in the past.

With respect to the relationship between pharmacists' intentions to provide two types of CPSs, respondents' intention to provide auxiliary CPSs was found to have a significant and positive relationship with their intention to provide core CPSs. Meanwhile, the respondents' intention to provide auxiliary CPSs was the most influential factor on their intention to provide core CPSs, which enhances the predictive power of the TPB model dealing with the context of the issues about new health services at different stages of development in the current study. Stated differently, pharmacists' intention to provide core CPSs is highly correlated to their support for themselves to participate in auxiliary work with physicians in clinical services practices. This suggests that pharmacists who value capitalising on their drug therapy expertise through auxiliary CPSs are more likely to provide higher-level core CPSs.
Consequently, this finding and the other results of this study have implications for the Chinese hospital pharmacy policymaker. The Chinese health authority should develop a step-by-step political agenda for core CPSs in hospital settings. First, pharmacists' intention to provide auxiliary CPSs is the most significant predictor of their intention to provide core CPSs. Therefore, in order to facilitate hospital pharmacists to form high intention to interact positively and more frequently with physicians at the ward level, it is vital to improve hospital pharmacists' intention to provide various auxiliary work. Considering the effects of $\mathrm{PBC}$ and $\mathrm{PB}$ on pharmacists' intention to provide auxiliary CPSs, it is desirable to encourage them to involve in medication-related services and improve hardware and software environment for CPSs in hospital care. Second, this study reveals that attitude towards CPSs is a more important influential factor on pharmacists' intention to provide two types of CPSs. Additionally, SN, the perceived social pressure from other important people, was found to significantly affect pharmacists' intention to provide core CPSs. Therefore, it is desirable to enlighten medical personnel (eg, pharmacist, physicians, nurses) and patients imprint into their minds the fact that traditional tasks of a hospital pharmacist have been changed to patient-centred case-based CPSs and the role of CPSs is very beneficial to the efficacy of pharmacotherapy in hospital settings. However, the TPB used in this study does not account for some external factors that affect the implementation of CPSs. For instance, previous research has highlighted that financial incentives to doctors and hospitals may negatively impact the implementation of CPSs. ${ }^{13}$ Furthermore, there is growing concern of mistrust by patients in healthcare professionals in China, which may further compound the issue. $^{42}$

\section{Limitations}

The study had several limitations. First, our sample came from urban general hospitals, limiting generalisability to the entire healthcare systems. Second, due to memory biases, consistency or social desirability, self-reported measures of behavioural intention and PBs in this study can possibly overestimate the association between PB and behavioural intention. ${ }^{43}$ Third, this cross-sectional study is unable to make causal inferences between TPB factors and actual behaviour because it did not control for all possible confounding variables. Testing this causal relationship would require a prospective study design. Finally, we could not conduct special elicitation interviews to gather the specific beliefs from the pharmacists, which limits the factors that affect pharmacists' intentions within the framework of TPB. Some important external factors, such as financial incentives to doctors and hospitals, could not be accounted for.

\section{CONCLUSION}

Pharmacists showed a positive intention, attitude, SN and PBC over provision of two types of CPSs. Attitude, 
$\mathrm{PBC}$ and $\mathrm{PB}$ were significant and positive predictors of intention to provide auxiliary CPSs. Attitude, SN and the pharmacists' intention to provide auxiliary CPSs were significant and positive predictors of their intention to provide core CPSs. Together, attitude, SN, PB and intention to provide auxiliary CPSs accounted for $54.0 \%$ of the variance in pharmacists' intention to provide core CPSs. The TPB with the addition of PB is a useful framework for predicting pharmacists' intention to provide CPSs in Chinese hospital care context. Strategies to improve pharmacists' intentions to provide CPSs should focus on helping medical personnel (eg, pharmacist, physicians, nurses) and patients see the value of CPSs, altering their perception of social pressure towards core CPSs and the removal of psychosocial and environmental obstacles that impede the translation of intentions into behaviour.

\section{Author affiliations}

${ }^{1}$ Department of Psychology, School of Health Policy and Management, Nanjing Medical University, Nanjing, People's Republic of China ${ }^{2}$ Department of Psychology, School of Education Science, Jiangsu Normal University, Xuzhou, People's Republic of China

${ }^{3}$ Department of English Languages, School of Foreign Languages, Nanjing Medical University, Nanjing, People's Republic of China

${ }^{4}$ Department of Health Policy, School of Health Policy and Management, Nanjing Medical University, Nanjing, People's Republic of China ${ }^{5}$ Department of Clinical Pharmacy, School of Pharmacy, Nanjing Medical University, Nanjing, People's Republic of China

Acknowledgements The authors would like to express their appreciation for all the research assistants in data collection.

Contributors YH conceived the survey and drafted the manuscript. FY conceived and designed the survey. DM drafted and revised the manuscript. $Y X$ performed the survey and analysed the data. XL conceived and designed the survey, analysed the data and drafted the manuscript.

Funding This research was supported by the National Natural Science Foundation of China (grant number 71003055), the General Project of Natura Science of University of Jiangsu Province (grant number 12KJB180008) and the Scholarship of Jiangsu Province Government Sponsorship for Overseas Study.

Competing interests None declared.

Ethics approval Ethical approval to conduct this study was obtained from the Nanjing Medical University Ethics Committee (grant number: ethical review 201236).

Provenance and peer review Not commissioned; externally peer reviewed.

Data sharing statement No additional data are available.

Open Access This is an Open Access article distributed in accordance with the Creative Commons Attribution Non Commercial (CC BY-NC 4.0) license, which permits others to distribute, remix, adapt, build upon this work noncommercially, and license their derivative works on different terms, provided the original work is properly cited and the use is non-commercial. See: http:// creativecommons.org/licenses/by-nc/4.0/

\section{REFERENCES}

1. American College of Clinical Pharmacy (ACCP). The definition of clinical pharmacy. Pharmacotherapy 2008;28:816-7.

2. $\mathrm{Ng} \mathrm{J}$, Harrison J. Key performance indicators for clinical pharmacy services in New Zealand public hospitals: stakeholder perspectives. $J$ Pharm Health Ser Res 2010;1:75-84.
3. Anderson SV, Schumock GT. Evaluation and justification of clinical pharmacy services. Expert Rev Pharmacoecon Outcomes Res 2009;9:539-45.

4. Bond CA, Raehl CL. Clinical pharmacy services, pharmacy staffing, and hospital mortality rates. Pharmacotherapy 2007;27:481-93.

5. De Rijdt T, Willems L, Simoens S. Economic effects of clinical pharmacy interventions: a literature review. Am J Health Syst Pharm 2008;65:1161-72.

6. Perez A, Doloresco F, Hoffman JM, et al. Economic evaluations of clinical pharmacy services: 2001-2005. Pharmacotherapy 2009;29:128.

7. Chan P, Grindrod KA, Bougher D, et al. A systematic review of remuneration systems for clinical pharmacy services. Can Pharmacists J 2008;141:102-12.

8. Grindrod KA, Rosenthal M, Lynd LD, et al. Pharmacists perspectives on providing chronic disease management services in the community: Part 1-current practice environment. Can Pharmacists J 2009;142:234-9.

9. Bell HM, McElnay J, Hughes $\mathrm{CM}$, et al. A qualitative investigation of the attitudes and opinions of community pharmacists to pharmaceutical care. J Soc Adm Pharm 1995;15:284-95.

10. Mottram DR, Jogia $P$, West $P$. The community pharmacists attitudes toward the extended role. J Soc Adm Pharm 1995;12:12-17.

11. Hu M, Jiang $\mathrm{XH}, \mathrm{Wu} \mathrm{YP}$, et al. Survey on hospital pharmaceutical care in China and the status quo of clinical pharmacy practice (part 2): survey on status quo of clinical pharmacy practice. Chin Pharm 2009;20:1030-2.

12. Li X, Zhang H, Wang J, et al. Assessing patient satisfaction with medication related services in hospital settings: a cross-sectional questionnaire survey in China. Int J Clin Pharmacol Ther 2014:52:587-97.

13. Penm J, Moles $\mathrm{R}$, Wang $\mathrm{H}$, et al. Factors affecting the implementation of clinical pharmacy services in China. Qual Health Res 2014;24:345-56.

14. Martin BA, Bruskiewitz RH, Chewning BA. Effect of a tobacco cessation continuing professional education program on pharmacists' confidence, skills, and practice-change behaviors J Am Pharm Assoc 2003 2010;50:9-16.

15. $\mathrm{Yu} \mathrm{CH}$, Batty HP. Targeting educational interventions to clinician's stage of change. Diabetes Res Clin Pract 2010;89:e43-45.

16. Schellart AJ, Zwerver F, Anema JR, et al. Relationships between the intention to use guidelines, behaviour of insurance physicians and their determinants. BMC Health Serv Res 2013;9:400.

17. Ajzen I, Madden TJ. Prediction of goal-directed behavior: attitudes, intentions, and perceived behavioral control. J Exp Soc Psychol 1986;22:453-74.

18. Abdi J, Eftekhar $\mathrm{H}$, Mahmoodi $\mathrm{M}$, et al. Physical activity status and position of governmental employees in changing stage based on the trans-theoretical model in Hamadan, Iran. Glob J Health Sci 2015:24:41888

19. Ajzen I. The theory of planned behavior. Organ Behav Hum Decis Process 1991:50:179-211.

20. Odedina FT, Segal R, Hepler CD. Changing pharmacists' practice pattern: pharmacists' implementation of pharmaceutical care factors. J Soc Administrative Pharm 1996;13:74-88.

21. Herbert KE, Urmie JM, Newland BA, et al. Prediction of pharmacis intention to provide Medicare medication therapy management services using the theory of planned behavior. Res Social Adm Pharm 2006;2:299-314

22. Pradel FG, Obeidat NA, Tsoukleris MG. Factors affecting pharmacists' pediatric asthma counseling. J Am Pharm Assoc (2003) 2007;47:737-46.

23. Walker A, Watson M, Grimshaw J. Applying the theory of planned behaviour to pharmacists' beliefs and intentions about the treatment of vaginal candidiasis with non-prescription medicines. Fam Pract 2004:21:670-6.

24. Gavaza P, Brown CM, Lawson KA, et al. Examination of pharmacists' intention to report serious adverse drug events (ADEs) to the FDA using the theory of planned behavior. Res Social Adm Pharm 2011;7:369-82.

25. Williams SD, Phipps DL, Ashcroft D. Examining the attitudes of hospital pharmacists to reporting medication safety incidents using the theory of planned behaviour. Int J Qual Health Care 2015;27:297-304

26. Gavaza P, Fleming M, Barner JC. Examination of psychosocial predictors of Virginia pharmacists' intention to utilize a prescription drug monitoring program using the theory of planned behavior. Res Social Adm Pharm 2014;10:448-58.

27. Fleming ML, Barner JC, Brown CM, et al. Using the theory of planned behavior to examine pharmacists' intention to utilize a 
prescription drug monitoring program database. Res Social Adm Pharm 2014;10:285-96.

28. Armitage CJ, Conner M. Efficacy of the theory of planned behaviour: a meta-analytic review. Br J Soc Psychol 2001;40:471-99.

29. International Pharmaceutical Federation. The Basel Statements on the future of hospital pharmacy. Am J Health Syst Pharm 2009;66:S61-6.

30. Li X, Huo H, Kong W, et al. Physicians' perceptions and attitudes toward clinical pharmacy services in urban general hospitals in China. Int J Clin Pharm 2014;36:443-50.

31. Quellette JA, Wood W. Habit and intention in everyday life: The multiple processes by which past behavior predicts future behavior. Psychol Bull 1998;124:54-74.

32. Fishbein M. A reasoned action approach to health promotion. Med Decis Making 2008;28:834-44.

33. Holland RW, Nimmo CM. Transitions in pharmacy practice, Part 3 : effecting change-The three-ring circus. Am J Health Syst Pharm 1999;56:2235-41.

34. Pavlou PA, Liang $\mathrm{H}$, Xue Y. Understanding and mitigating uncertainty in online environments: an agency theory perspective. MIS Q 2007;31:105-36.

35. Chin WW. Issues and opinion on structural equation modeling MIS Q 1998;22:7-16.

36. Pedersen CA, Schneider PJ, Scheckelhoff DJ. ASHP national survey of pharmacy practice in hospital settings: monitoring and patient education--2012. Am J Health Syst Pharm 2013;70:787-803.
37. Armitage CJ, Sheeran $\mathrm{P}$, Conner M, et al. Stages of change or changes of stage? Predicting transitions in transtheoretical mode stages in relation to healthy food choice. J Consult Clin Psychol 2004:72:491-9.

38. Sheeran P, Trafimow D, Armitage CJ. Predicting behavior from perceived behavioural control: tests of the accuracy assumption of the theory of planned behaviour. Br J Soc Psychol 2003;42:393-410.

39. Sheeran $\mathrm{P}$, Orbell S. Do intentions predict condom use? Meta-analysis and examination of six moderator variables. $\mathrm{Br} J$ Soc Psychol 1998;37(Pt 2):231-50.

40. Connor M, Sparks P. Theory of planned behaviour and health behaviour. In: Connor M, Norman P, eds. Predicting health behaviour. 2nd edn. Maidenhead: Open University Press, 2005:170-222.

41. Quine L, Rutter DR, Arnold L. Predicting and understanding safety helmet use among schoolboy cyclists: a comparison of the theory of planned behaviour and the health belief model. Psychol Health 1998;13:251-69.

42. Zhang Y, Harvey K. Rational antibiotic use in China: lessons learnt through introducing surgeons to Australian guidelines. Aust New Zealand Health Policy 2006;30:5

43. Webb TL, Sheeran P. Does changing behavioral intentions engender behavior change? A meta-analysis of the experimental evidence. Psychol Bull 2006;132:249-68. 